\title{
ПРОЦЕССНЫЙ ПОДХОД КАК МЕТОДОЛОГИЧЕСКАЯ ОСНОВА ЭКОНОМИЧЕСКОЙ ИНТЕГРАЦИИ ЗАБАЙКАЛЬСКОГО КРАЯ И СОПРЕДЕЛЬНЫХ ТЕРРИТОРИЙ КНР
}

\author{
Л. Б. Ковальчук' ${ }^{1}$, Я. А. Суходолов ${ }^{2}$ \\ 1 Читинский институт (филиал) Байкальского государственного университета, г. Чита, \\ Российская Федерация \\ 2 Министерство международного сотрудничества и внешнеэкономических связей Забайкальского края, \\ г. Чита, Российская Федерация
}

\section{Информация о статье}

Дата поступления

13 марта 2018 г.

Дата принятия к печати 21 мая 2018 г.

Дата онлайн-размещения 8 июня 2018 г.

\section{Ключевые слова}

Теория отношений; международная региональная интеграция; процессный подход; взаимодействие процессов; гармонизация отношений; клиенты; владельцы процессов; акторы

\begin{abstract}
Аннотация
В статье обосновывается необходимость развития международной экономической интеграции между Забайкальским краем и сопредельными территориями КНР. Развитие региональной интеграции, с точки зрения автора, позволит краю реализовать свои конкурентные преимущества. Возможность углубления региональной интеграции между Забайкальским краем и КНР основана на взаимодополняемости и взаимозависимости потенциалов развития обеих сторон. При этом существующие национальные различия сопредельных региональных социально-экономических систем обусловливают необходимость формирования общей системы целей, согласования приоритетов в их достижении, что, в свою очередь, подразумевает формирование согласованной интеграционной политики двух регионов - Забайкальского края и автономного района Внутренняя Монголия. При этом формирование такой политики сдерживается отсутствием единой теоретико-методологической основы международной региональной интеграции. В условиях множественности и неоднозначности научных подходов к исследованию международной системы в качестве научного базиса международной региональной интеграции предлагается рассматривать «теорию отношений» профессора Цинь Яцина, который обосновывает необходимость и возможность гармонизации отношений между участниками международных обменов. По нашему мнению, практическая реализация положений «теории отношений» возможна в рамках процессного подхода, который подразумевает взаимодействие участников международной интеграции в достижении общих результатов. Нацеленность участников процесса позволяет организовать их взаимодействие в формате взаимодополняемости, что обусловливает возможность достижения не только более высоких результатов, но и гармонии в их взаимоотношениях в широком долгосрочном контексте. Использование процессного подхода в качестве методологической основы региональной интеграции дает возможность согласовать цели, сбалансировать интересы сторон интеграции, определить приоритеты. Предложенная Цинь Яцином парадигма международных отношений дополнена классификацией процессов, оценкой их влияния на результат, характером взаимодействия. Показано, что взаимодействие процессов является достаточно устойчивым, предсказуемым, управляемым, следовательно, использование процессного подхода в целях развития международной региональной интеграции представляется весьма перспективным. На основе процессного подхода возможно формирование сценариев развития международной интеграции с разным составом, уровнем результативности и характером взаимодействия процессов.
\end{abstract}


PROCESS APPROACH AS A METHODOLOGICAL BASIS FOR ECONOMIC INTEGRATION OF THE TRANS-BAIKAL TERRITORY AND THE ADJACENT TERRITORIES OF CHINA

\author{
Lyudmila B. Kovalchuk', Yakov A. Sukhodolov ${ }^{2}$ \\ ${ }^{1}$ Chita Institute (Branch) of Baikal State University, Chita, the Russian Federation \\ ${ }^{2}$ Ministry of International Cooperation and Foreign Trade of Zabaikalsky Region, Chita, the Russian Federation
}

Article info

Received

March 13, 2018

Accepted

May 21, 2018

Available online

June 8, 2018

\section{Keywords}

Theory of relationships;

international regional integration; process approach; interaction of the processes; harmonization of the relationships; customers; process owners; actors

\begin{abstract}
The article proves the necessity of international economic integration between the Trans-Baikal region and the adjacent territories of China. From the author's point of view, the development of regional integration will allow the region to realize its competitive advantages. The possibility of increasing regional integration between the Trans-Baikal territory and China is based on complementarity and interdependence of the economic potentials of both sides. At the same time, the existing national differences at the level of development of the adjacent socio-economic systems need a common system of goals, balance of priorities in their achievement, which, in its turn, implies a coherent integration policy between the two regions - the Trans-Baikal territory and Inner Mongolia Autonomous Region. At the same time, lack of unified theoretical and methodological basis for international regional integration restrains the formation of such a policy. In the context of multiple and ambiguous scientific approaches to the study of the international system, it is proposed to consider the "theory of relationships», by Professor Qin Yatsin, as the scientific basis for international regional integration, which proves the need and the possibility of harmonizing relationships between participants of international exchanges. From the author's point of view, the practical implementation of the "theory of relations» is possible within the framework of the process approach, which implies the interaction of participants of international integration in achieving overall results. The focus of the participants of the process makes it possible to organize their interaction in the form of complementarity, which means not only better results, but also harmony in their mutual relations in a long-term context. The use of the process approach as a methodological basis for regional integration allows to balance the interests of the sides of integration, to identify their priorities. The proposed paradigm of international relations is supplemented by the author's classification of the processes, the assessment of their impact on the results of integration. It is shown that the interaction of the processes is sufficiently stable, predictable, manageable, hence the use of the process approach in the development of international regional integration seems very promising. Process approach allows to form various scenarios of international integration, based on different composition, results and nature of the interacting processes.
\end{abstract}

Забайкальский край имеет самую протяженную по сравнению с другими российскими регионами границу с КНР. Внешнеэкономическая деятельность входит в число приоритетных направлений регионального экономического развития. Международные проекты достаточно органично встроены в стратегию социально-экономического развития. Подписаны многочисленные договоры ○ сотрудничестве между сопредельными территориями Китая и Забайкальским краем. Результаты сотрудничества отражают данные статистики (табл.).
Динамика товарооборота Забайкальского края с КНР, \% к предыдущему году

\begin{tabular}{|l|r|r|l|r|r|}
\hline Показатель & \multicolumn{1}{|c|}{2012} & \multicolumn{1}{c|}{2013} & 2014 & \multicolumn{1}{c|}{2015} & \multicolumn{1}{c|}{2016} \\
\hline Оборот с КНР & 96,4 & 100,8 & 104,2 & 88,9 & 90,5 \\
\hline Экспорт & 88,3 & 77,4 & 110,6 & 126,8 & 105,9 \\
\hline Импорт & 97,9 & 104,7 & 103,4 & 84,1 & 87,6 \\
\hline
\end{tabular}

В условиях благоприятной конъюнктуры товарных и финансовых рынков ощутимо растет экспорт продукции из Забайкальского края, увеличивается коэфффициент покрытия импорта экспортом (до 19 \%). При этом обращает на себя внимание то, что 
динамика товарооборота за последние пять лет неустойчивая, что, очевидно, связано со скачкообразными колебаниями спроса на мировых сырьевых рынках, на которые в значительной мере ориентируется экономика Забайкальского края. В товарной структуре края доминирует топливно-минеральное сырье $(33,8 \%)$, древесина и изделия из нее $(44,4 \%)$. Тенденции роста объемов товарного экспорта не распространяются на экспорт услуг, который в исследуемом периоде заметно сократился (на 54 \%). В общем объеме экспорта основную долю составляли транспортные услуги, услуги гостиниц и ресторанов, бюро путешествий и экскурсий, а также туристических агентов.

Отмеченные позитивные изменения показателей внешнеэкономической деятельности Забайкальского края и КНР, с нашей точки зрения, следует рассматривать как незначительное улучшение условий торговли с КНР, которое не связано с прогрессивной трансформацией международного сотрудничества в направлении углубления интеграции. Приходится констатировать, что существующий уровень международного сотрудничества Забайкальского края и сопредельных территорий КНР не обеспечивает возможности полномасштабного использования имеющихся в крае конкурентных преимуществ: достаточно развитой транспортно-логистической инфраструктуры, обеспеченности природными ресурсами, наличия адаптированного к суровым климатическим условиям сельского хозяйства, обеспеченного необходимыми вспомогательными и перерабатывающими производствами.

Вместе с тем в условиях глобализации мирового хозяйства углубление интеграционных связей с государством, занимающим одну из ключевых позиций в мировом бизнесе, открывает заманчивые перспективы расширения рынков сбыта для отечественных сельхозпроизводителей и предприятий продовольственного сектора, внедрения передовых технологий в сфере добычи и переработки минерального сырья, создания высокотехнологичных производств в сорере производства машин и оборудования, ракетно-космического сектора, развития индустрии туризма и гостеприимства, решения большого числа социальных проблем.

Возможность более глубокой интеграции экономики Забайкальского края и автономного района Внутренняя Монголия (КНР), с нашей точки зрения, имеется, и основана она на взаимодополняемости потенциалов развития обеих сторон. Так, вовлечение в промышленный оборот богатых природных ресурсов Забайкальского края может быть обеспечено инвестиционными возможностями китайской стороны и дополнено прогрессивным инвестиционным законодательством Забайкальского края, обеспечивающим иностранным инвесторам льготный налоговый режим и поддержку правительства, имеющего позитивный опыт взаимодействия с бизнес-структурами сопредельных территорий КНР и Монголии.

В контексте взаимодополняемости следует также отметить и постоянно повышающийся платежеспособный спрос на экологически чистую продукцию сельскохозяйственного и промышленного производства на рынках в КНР, и наличие соответствующих производственных мощностей, технологий и опыта работы таких производств в Забайкальском крае. При этом, учитывая тенденции развития мирового хозяйства и ускорения его глобализации, можно прогнозировать рост не только взаимодополняемости, но и взаимозависимости хозяйств приграничных территорий указанных государств, которая, кроме положительных результатов, сопровождается серьезными вызовами стабильности и экономической безопасности со стороны экономик ряда западных стран. Очевидно, что необходима гармонизация возможностей и угроз, возникающих в контексте международного сотрудничества между регионами сопредельных государств [1]. Полагаем, что для этого международное сотрудничество Забайкальского края и КНР должно продвигаться по пути углубления интеграции, перехода на более высокий уровень, предполагающий прежде всего согласование целей, определение приоритетов, оптимизацию результатов международного регионального сотрудничества. С учетом различий в национальных политико-правовых, социальных, экономических, технологических средах достижение согласия и согласованности участников интеграции должно опираться на общее, разделяемое всеми сторонами международного обмена представление о системе международных отношений, которое формирует теоретико-методологический базис организации и управления региональной интеграцией [2].

В условиях множественности и неоднозначности существующих научных подходов достаточно перспективным представляется подход, разработанный профрессором Цинь Яцином (китайский Университет иностранных дел) [3]. В рамках предложенного подхода международная система отношений рассма- 
тривается как совокупность взаимосвязей между людьми, обществами, событиями, вещами. В рамках такой системы отдельные, индивидуальные интересы подчинены интересам всего сообщества, в связи с чем система становится гармонизированной и более устойчивой [4]. Гармония отношений, занимающая центральное место в методологии китайских исследователей, отличает ее от западных представлений и подходов, которые в качестве основных элементов международной системы рассматривают отдельных акторов с их субъективными амбициями, индивидуальными целями и конкурентными преимуществами [5]. Очевидно, что западные представления, закрепленные в международных соглашениях и установленных на мировом рынке правилах игры, обусловливают доминирование отдельных, наиболее сильных акторов, приоритет их интересов и разбалансировку всей системы международных отношений, проявляющуюся кризисами и периодами турбулентности [6]. Дисгармония в отношениях между участниками международного сотрудничества, как показывает практика, приводит к разрыву в их уровне социально-экономического развития и формирует, таким образом, экономическую и политическую зависимость участников [7].

Предложенные китайскими исследователями методологические основы системы международных отношений в последнее время находят достаточно активную поддержку среди ведущих российских специалистов. Так, профессор МГУ Евгений Грачиков в качестве одного из аргументов в поддержку представленного китайскими учеными направления отмечает, что гармония в указанном контексте достигается путем «взаимного включения» (через Чжунюн), через процесс, который... путем объединения противоположностей и устранения конфликтов, обеспечивает достижение результата» [8]. В этой связи рассматриваемая теория открывает новые перспективы развития международного сотрудничества и региональной интеграции, так как, «совместно развиваясь без взаимного устранения, они [процессы] формируют новую жизнь. Нормы и институты Запада и Востока встречаются, взаимодействуют и развиваются в новые формы, которые взаимно включены, взаимодействуют и, таким образом, являются более надежными» [9].

В контексте развития региональной интеграции между КНР и Забайкальским краем актуальность разработанных китайскими учеными методологических основ формирования международных отношений и международного сотрудничества не вызывает сомнений. При этом с учетом определенной научной новизны рассматриваемой методологии представляется необходимым привести некоторые дополнительные аргументы в поддержку предложенных подходов для их реализации на региональном уровне.

Прежде всего, следует обратить внимание на то, что процессы, связывающие отдельных акторов (владельцев и клиентов) процессов, должны быть нацелены на результат, удовлетворяющий интересы всех акторов [10]. При этом подчеркнем, что реализация процесса не требует от его участников отказа от собственной аутентичности, которая как раз и позволяет достичь наиболее высокого результата. Кроме этого, в качестве аргумента в поддержку подхода Цинь Яцина необходимо отметить также и то, что результат любого процесса можно оценить количественно. Возможность оценки результатов процессов позволяет осуществлять эффрективное управление ими, включая планирование, прогнозирование процессов и контроль за их формированием и протеканием.

В контексте управления структурирование взаимоотношений между отдельными участниками в форме процессов позволяет сорормировать систему целей всех участников процесса, согласованных на разных уровнях, сбалансировать интересы разных сторон, оценить обеспеченность целей необходимыми ресурсами, выработать общий алгоритм их осуществления, определить результаты, владельцев и клиентов каждого процесса. Следует отметить, что процессное управление в международной сфере не вступает в противоречие с таким распространенным в последнее время «проектным» управлением и не отменяет его. В отличие от проекта, который имеет специфический и уникальный характер, процесс - постоянно повторяющая последовательность действий и возобновляющихся отношений, которые могут быть многократно модифицированы и, в отличие от проекта, оптимизированы. Таким образом, процессы являются предсказуемыми, рациональными, а их управление поддается автоматизации.

Важным аргументом в поддержку процессного подхода в сорере международного сотрудничества и региональной интеграции служит и то, что он приобретает все большую популярность в бизнесе, обеспечивая высокую конкурентоспособность 
продукции не только на внутреннем, но и на внешнем рынке.

В представлении Цинь Яцина основу взаимоотношений составляют процессы «инь» и «янь», которые он считает фундаментальными [11].

С позиции региональных социально-экономических систем и возможностей их интеграции в качестве интерпретации «фундаментальных» процессов, по нашему мнению, следует рассматривать социальные и экономические процессы, протекающие на разных уровнях этих систем. Формирование и появление новых процессов связано с необходимостью удовлетворять разнообразные и многочисленные потребности населения. С точки зрения универсальности человеческих потребностей ядро социально-экономической системы составляют процессы, обеспечивающие жизнедеятельность. При этом в разных региональных системах указанные процессы имеют одинаковый состав. Именно данные процессы, на наш взгляд, могут составлять основу международной региональной интеграции. Интерпретируя результаты исследования Цинь Яцина и дополняя парадигму разработанной им «теории отношений», представим состав региональных процессов, формирующих, с нашей точки зрения, основу региональной интеграции [12; 13].

В сорере экономики нами были выделены процессы, удовлетворяющие следующие потребности: потребность в пище, жилье, инновациях, промышленных товарах, потребность в самостоятельном безопасном передвижении. В состав социальных процессов нами был включены процессы, удовлетворяющие такие потребности, как потребность в труде, восстановлении здоровья, образовании, информации, культурном развитии. Проведенные нами исследования результатов процессов на региональном уровне позволили определить характер их взаимодействия и установить, что в зависимости от условий функционирования региональной системы он может быть положительным (доминантным), т. е. обеспечивающим условия для достижения системообразующей цели, и отрицательным (рецессивным), негативно влияющим на совокупную результативность социально-экономического развития системы [14]. С учетом выявленных особенностей взаимодействия региональных процессов можно предложить дополнить парадигму «теории отношений» Цинь Яцина следующей классификацией процессов: аквизитивные процессы - процессы, преобразующие ресурсы входов в полезные для участников результаты; диссипативные процессы - процессы рассеивания ресурсов, поступающих из внешней среды, создающие «помехи» или «барьеры» для создания полезных с точки зрения участников процессов результатов.

Аквизитивные и диссипативные процессы взаимодействуют друг с другом при удовлетворении потребностей и достижении целей осуществления процессов. С точки зрения управления процессами деление их на аквизитивные и диссипативные позволяет оптимизировать состав региональных процессов, минимизируя барьеры и стирая помехи, перенаправляя ресурсы входа в аквизитивные процессы, создающие полезные результаты [15].

Управление составом региональных процессов может осуществляться на основе перераспределения ресурсов между входами в различные процессы. Как показали исследования, между процессами при их взаимодействии происходит активное перераспределение ресурсов, сопровождающееся рассеиванием их части. В результате перераспределения формируется либо синхронизированная динамика результативности процессов, “условие максимума», либо ее противофазовость (пики в динамике результативности одних процессов совпадают со спадами в динамике результативности других процессов), «условие минимума». Синхронность или противофазовость пиков и спадов в динамике результативности - проявление механизма согласованности (когерентности) региональных процессов. Перераспределение ресурсов между процессами представляет собой инструмент обеспечения согласованности (когерентности), которая приводит к синергетическому эффректу результативности всей социально-экономической системы.

В контексте региональной интеграции представленная классификация региональных процессов и выявленные механизмы их взаимодействия (когерентность) обусловливают возможность разработки различных сценариев ее реализации, отличающихся высокой результативностью процессов [16].

Одним из наиболее перспективных с точки зрения имеющихся потребностей населения и сложившихся условий проживания представляется сценарий, подразумевающий взаимодействие интеграционных процессов с высокой динамикой и высоким уровнем результативности. Указанное взаимодействие может осуществляться как в одной сфрере (например, между процессами экономической сферы (строительство, производство 
сельхозпродукции, развитие коммуникаций) или процессами социальной сферы, включающими образование, науку, медицину, гуманитарное сотрудничество и т. п.), так и между разными сорерами - экономикой и социальной сорерой (например, процессы, обеспечивающие удовлетворение потребности в труде, и процессы, обеспечивающие удовлетворение потребностей в жилье, инновациях и т. п.).

Достаточно перспективным представляется также взаимодействие процессов, имеющих разный характер (аквизитивных и диссипативных). Целью такого взаимодействия может быть устранение имеющихся барьеров и проблем, имеющих глобальный и (или) региональный характер. Например, устранение потерь при переработке ресурсов, предупреждение утечки квалифицированных кадров, фрормирования различных институциональных ловушек и т. п.

Другим направлением международного регионального сотрудничества, обеспечивающим высокую результативность, представляется взаимодействие процессов, динамика которых совпадает (однофазовые процессы) или является противоположной (противофразовые процессы). Указанные процессы могут обеспечить высокую результативность, синергетический эффрект международной региональной интеграции, который, в свою очередь, обусловит начало глубокой прогрессивной трансформации интеграционных процессов. Возможность трансформации, т. е. коренного изменения характера взаимодействия, возможность перехода на более высокий уровень интеграции обусловливает более рациональное использование совместного ресурсного потенциала сотрудничества, достигнутого перераспределением ресурсов между аквизитивными и диссипативными процессами, устранением потерь ресурсов при осуществлении процессов, более точной ориентаций на клиентов и более полным удовлетворением их потребностей.

Таким образом, реализация процессного подхода представляется достаточно обоснованной и реалистичной в организации управления региональной интеграцией, повышающей ее результативность, активность и эфффективность. При этом следует отметить, что перспективы реализации данного подхода в управлении международной интеграцией на региональном уровне зависят от возможности устранения определенных проблем и сложностей, связанных с внедрением предложенного подхода.

Одна из таких проблем - достаточная трудоемкость организации процессного подхода на практике. Другой видимой проблемой, на наш взгляд, выступают значительные трудности с организацией контроля за результатами процессов на международном уровне. Немаловажным видится и наличие специалистов, имеющих достаточный опыт участия в организации процессов на предприятиях, осуществляющих внешнеэкономическую деятельность.

Представленные проблемы, на наш взгляд, не являются неразрешимыми и не могут служить основанием для отказа по меньшей мере от исследования проблем применения процессного подхода в сфере международной интеграции и поиска новых механизмов ее продвижения.

\section{СПИСОК ИСПОЛЬЗОВАННОЙ ЛИТЕРАТУРЫ}

1. Воскресенский А. Д. Мировое комплексное регионоведение и перспективы построения незападной (китаизированной) теории международных отношений / А. Д. Воскресенский // Полис. Политические исследования. - 2013. - № 6. - С. 82-96.

2. Hoffman S. An American Social Science: International Relations / S. Hoffman / / Deadalus. — 1977. — Vol. 106, № 3. - P. 41-60.

3. Арин О. И. Теории международных отношений с китайской спецификой [Электронный ресурс] / O. И. Арин. - Режим доступа: http://olegarin.com/olegarin/TEORII_MEZDUNARODNYH_OTNOSENIJ_S_ KITAJSKOJ_SPECIFIKOJ.html.

4. Арин О. И. От Сунь Цзы до Джозефа Ная / О. И. Арин / / Азия и Африка сегодня. — 2013. - № 3. C. 55-61.

5. Понька Т. И. Китайский взгляд на теорию международных отношений / Т. И. Понька, А. С. Бельченко, А. А. Забелла / / Мировая экономика и международные отношения. — 2017. - Т. 61, № 10. - C. 76-86. DOI: 10.20542/0131-2227-2017-61-10-76-86.

6. Чжао Тинян. Современный взгляд на китайскую мечту / Чжао Тинян / / Международные процессы. 2015. - T. 13, № 41. - C. 21-34.

7. Qin Yaqing. 结构, 进程与权力的社会化：中国与东亚地区合作 [Structures, Processes and the Socialization of Power: China and the Regional Cooperation in East Asia (In Chin.)] / Qin Yaqing, Ling Wang / / World Economics and Politics. - 2007. - № 3. - P. 7-15.

8. Грачиков Е. Н. Международные отношения в современном Китае: институционализация дисциплины / Е. Н. Грачиков / / Международные процессы. - 2014. - Т. 12, № 39. - С. 49-65. 
9. Do T. T. China's Rise and the 'Chinese Dream' in International Relations Theory / T. T. Do / / Global Change, Peace \& Security. - 2015. - Vol. 27, № 1. - P. 21-38.

10. Козинец А. И. Факторы развития современных китайских подходов в теории международных отношений / А. И. Козинец / / Вестник Забайкальского государственного университета. - 2016. - Т. 22 , № $1 .-$ C. 66-77.

11. Qin Yaqing. Guanxi yu Guocheng: Zhongguo Guoji Guanxi Lilun de Wenhua Jiangou [Relations and Processes: Cultural Construction of Chinese IR Theory. Shanghai: Shanghai Peoples Publishing House] / Qin Yaqing / / Shijie jingji yu zhengzhi (World Economics and Politics). - 2008. - Vol. 11.

12. Кузнецов А. М. «Мирное развитие Китая» инекоторыепроблемысовременной теории международных отношений / А. М. Кузнецов / / Политическая концептология. — 2014. — № 3. - С. 166-177.

13. Цыганков П. А. Проблема мирового порядка в китайской и российской политической науке: общее и особенное / П. А. Цыганков, Е.Н.Грачиков / / Политическая наука. - 2015. - № 4. - С. 22-39.

14. Ковальчук Л. Б. Применение процессного подхода в управлении региональной социальноэкономической системой [Электронный ресурс] / Л. Б. Ковальчук // Известия Иркутской государственной экономической академии (Байкальский государственный университет экономики и права). - 2015. - Т. 6, № 2. - Режим доступа: http://eizvestia.isea.ru/reader/article.aspx?id=20024. — DOl: 10.17150/20720904.2015.6(2).12.

15. Ковальчук Л.Б. Когерентностьпроцессов материальногои социальногоблагосостоянияв региональном развитии [Электронный ресурс] / Л. Б. Ковальчук // Известия Иркутской государственной экономической академии. - 2012. - № 3. - Режим доступа: http: / / brj-bguep.ru/reader/article.aspx?id=13587.

16. Суходолов Я. А. Российско-китайское внешнеторговое сотрудничество в контексте повышения национальной конкурентоспособности / Я. А. Суходолов ; под ред. Н. В. Гордеева. - Новосибирск : Наука, 2016. - $199 \mathrm{c}$.

\section{REFERENCES}

1. Voskresenskii A. D. International Integrated Regional Studies and Perspectives of Development of Non-Western (China-Oriented) International Relations Theory. Polis. Politicheskie issledovaniya = Polis. Political studies, 2013, no. 6, pp. 82-96. (In Russian).

2. Hoffman S. An American Social Science: International Relations. Deadalus, 1977, vol. 106, no. 3, pp. 4160.

3. Arin O. I. Teorii mezhdunarodnykh otnoshenii s kitaiskoi spetsifikoi [China-Oriented International Relations Theories]. Available at: http://olegarin.com/olegarin/TEORII_MEZDUNARODNYH_OTNOSENIJ_S_KITAJSKOJ_ SPECIFIKOJ.html. (In Russian).

4. Arin O. I. Ot Sun' Tszy do Dzhozefa Naya [From Sun Zi to Joseph Nye]. Aziya I Afrika segodnya = Asia and Africa today, 2013, no. 3, pp. 55-61. (In Russian).

5. Ponka T. I., Belchenko A. S., Zabella A. A. Chinese View on the International Relations Theory. Mirovaya ekonomika I mezhdunarodnye otnosheniya = World Economy and International Relations, 2017, vol. 61, no. 10, pp. 76-86. DOI: 10.20542/0131-2227-2017-61-10-76-86. (In Russian).

6. Chzhao Tinyan. Modern View on the Chinese Dream. Mezhdunarodnye protsessy = International trends, 2015, vol. 13, no. 41, pp. 21-34. (In Russian).

7. Qin Yaqing, Ling Wang. 结构, 进程与权力的社会化：中国与东亚地区合作 [Structures, Processes and the Socialization of Power: China and the Regional Cooperation in East Asia (In Chin.)]. World Economics and Politics, 2007, no. 3, pp. 7-15.

8. Grachikov E. N. International Relations in Contemporary China Institualization of the Field. Mezhdunarodnye protsessy = International trends, 2014, vol. 12, no. 39, pp. 49-65. (In Russian).

9. Do T. T. China's Rise and the 'Chinese Dream' in International Relations Theory. Global Change, Peace \& Security, 2015, vol. 27, no. 1, pp. 21-38.

10. Kozinets A. I. Development Factors of Contemporary Chinese Approaches in the International Relations Theory. Vestnik Zabaikal'skogo gosudarstvennogo universiteta = Transbaikal State University Journal, 2016, vol. 22, no. 1, pp. 66-77. (In Russian)

11. Qin Yaqing. Guanxi yu Guocheng: Zhongguo Guoji Guanxi Lilun de Wenhua Jiangou [Relations and Processes: Cultural Construction of Chinese IR Theory. Shanghai, Shanghai Peoples Publishing House]. Shijie jingji yu zhengzhi (World Economics and Politics), 2008, vol. 11.

12. Kuznetsov A. M. "China>s peaceful development» and some problems of the modern theory of international relations. Politicheskaya kontseptologiya = The political conceptology, 2014, no. 3, pp. 166-177. (In Russian).

13. Tsygankov P. A., Grachikov E. N. A matter of the world order in the Chinese and Russian political science: general and particular. Politicheskaya nauka = Political Science, 2015, no. 4, pp. 22-39. (In Russian).

14. Kovalchuk L. B. Use of process approach in management of regional socio-economic system. Izvestiya Irkutskoi gosudarstvennoi ekonomicheskoi akademii (Baykalskii gosudarstvennyi universitet ekonomiki i prava) = Izvestiya of Irkutsk State Economics Academy (Baikal State University of Economics and Law), 2015, vol. 6, no. 2. Available at: http:/ / eizvestia.isea.ru/reader/article.aspx?id=20024. DOI: 10.17150/2072-0904.2015.6(2).12. (In Russian).

15. Kovalchuk L. B. Coherence of material and social welfare processes in regional development. Izvestiya Irkutskoi gosudarstvennoi ekonomicheskoi akademii (Baykalskii gosudarstvennyi universitet ekonomiki $i$ prava) = Izvestiya of Irkutsk State Economics Academy (Baikal State University of Economics and Law), 2012, no. 3. Available at: http: / /brj-bguep.ru/reader/article.aspx?id=13587. (In Russian).

16. Sukhodolov J. A.; Gordeev N. V. (ed.). Rossiisko-kitaiskoe vneshnetorgovoe sotrudnichestvo $v$ kontekste povysheniya natsionalnoi konkurentosposobnosti [Russian-Chinese Foreign Trade Cooperation within the framework of National Competitive Recovery]. Novosibirsk, Nauka Publ., 2016. 199 p. 


\section{Информация об авторах}

Ковальчук Людмила Борисовна - кандидат экономических наук, доцент, заместитель директора по учебной и научной работе, Читинский институт (филиал) Байкальского государственного университета, 672000, г. Чита, ул. Анохина, 56, e-mail: kovalchuklb@mail.ru.

Суходолов Яков Александрович - кандидат экономических наук, начальник отдела, Министерство международного сотрудничества и внешнеэкономических связей Забайкальского края, 672000, г. Чита, ул. Анохина, 37; e-mail: yakov.suchodolov@ gmail.com.

\section{Для цитирования}

Ковальчук Л. Б. Процессный подход как методологическая основа экономической интеграции Забайкальского края и сопредельных территорий КНР / Л. Б. Ковальчук, Я. А. Суходолов // Известия Байкальского государственного университета. - 2018. - T. 28, № 2. - C. 292-299. - DOl: $10.17150 / 2500-2759.2018 .28(2) .292-299$.

\section{Authors}

Lyudmila B. Kovalchuk - Ph.D. in Economics, Associate Professor, Deputy Director for Educational and Research Activities, Chita Institute (Branch) of Baikal State University, 56 Anokhin St., 672000, Chita, the Russian Federation, e-mail: kovalchuklb@mail.ru.

Yakov A. Sukhodolov - Ph.D. in Economics, Department Head, Ministry of International Cooperation and Foreign Trade of Zabaikalsky Region, 37 Anokhin St., 672000, Chita, the Russian Federation, e-mail: yakov.suchodolov@gmail.com.

\section{For citation}

Kovalchuk L. B., Sukhodolov Ya. A. Process Approach as a Methodological Basis for Economic Integration of the Trans-Baikal Territory and the Adjacent Territories of China. Izvestiya Baykal'skogo gosudarstvennogo universiteta $=$ Bulletin of Baikal State University, 2018, vol. 28, no. 2, pp. 292-299. DOl: 10.17150/2500-2759.2018.28(2).292-299. (In Russian). 